\title{
CONTRIBUIÇÕES DA TEORIA DA AÇÃO COMUNICATIVA DE JÜRGEN HABERMAS NOS MEIOS COMPLEMENTARES DE TRATAMENTO DE CONFLITO: O ESTUDO DO MULTIDOOR COURTHOUSE SYSTEM
}

\author{
Charlise Paula Colet Gimenez ${ }^{1}$ \\ Fabiana Marion Spengler ${ }^{2}$
}

\begin{abstract}
Resumo
O artigo apresenta as contribuições da Teoria da Ação Comunicativa aos meios complementares de tratamento de conflito, perfazendo, para tanto, um estudo de caso do Multidoor Courthouse System. Para a realização da pesquisa, utiliza-se o método de abordagem hipotético-dedutivo, enquanto método de procedimento monográfico. Dessa forma, relaciona-se a Teoria de Jürgen Habermas como meio de empoderamento e emancipação dos envolvidos no conflito, o que possibilita o cumprimento do objetivo do Tribunal Múltiplas Portas, qual seja, apresentar o tratamento mais adequado ao conflito.
\end{abstract}

Palavras-chave: Ação Comunicativa; Tratamento do Conflito; Tribunal Múltiplas Portas.

\section{CONSIDERAÇÕES INICIAIS}

A Teoria da Ação Comunicativa proposta pelo filósofo e sociólogo alemão Jürgen Habermas sustenta-se no discurso argumentativo para atingir o entendimento consensual, afirmando-se que a partir de uma situação ideal de fala as pessoas/sujeitos resolvem seus impasses, motivo pelo qual se estuda a teoria acima indicada como meio de emancipação e entendimento mútuo dos atores sociais.

A seu turno, o Sistema de Múltiplas Portas, denominado de Multidoor Courthouse System, foi pela primeira vez descrito na Conferência Pound de 1976, como alternativa diante das insuficiências das práticas da justiça até então realizadas nos Estados Unidos, as quais não atendiam satisfatoriamente às pessoas que buscavam um amparo judicial.

\footnotetext{
${ }^{1}$ Doutoranda em Direito e Mestre em Direito pela UNISC - Universidade de Santa Cruz do Sul e Especialista em Direito Penal e Processo Penal pela UNIJUÍ - Universidade Regional do Noroeste do Estado do Rio Grande do Sul. Professora de Direito Penal e Estágio de Prática Jurídica pela URI - Universidade Regional Integrada do Alto Uruguai e Missões (Santo Ângelo/RS). Membro do Grupo de Estudos "Políticas Públicas no Tratamento dos Conflitos" vinculado ao CNPq. Bolsista CAPES. Advogada. E-mail: charliseg@santoangelo.uri.br

2 Pós-doutora em Direito pela Università degli Studi di Roma Tre, em Roma na Itália, com bolsa CNPq (PDE). Docente dos cursos de Graduação e Pós Graduação lato e stricto sensu da UNISC. Coordenadora do Grupo de Pesquisa "Políticas Públicas no Tratamento dos Conflitos" vinculado ao CNPq. Advogada. E-mail: fabiana@unisc.br vol.09, nº. 01, Rio de Janeiro, 2016.pp. 164-180 
Dessa forma, o professor de Direito da Universidade de Harvard, Frank Sander, propôs um sistema de acesso a diferentes "portas", as quais se apresentam como métodos de tratamento de conflito, aplicáveis de acordo com o tipo do caso (mais apropriado).

Ao procurar o Judiciário, as partes passam por um processo de triagem quando há a escolha de um dos métodos de tratamento de conflito mais adequados às necessidades do litígio apresentado. Nessa ótica, apresentam-se como portas a mediação, a conciliação, a arbitragem, os processos híbridos, como a mediação e a arbitragem (med-arb ou arb-med), o mini-trial, o summary jury trial, o case evaluation, o ombudsman e a adjudicação.

Assim, com o presente estudo, objetiva-se desenvolver o estudo acerca do Tribunal Multiportas a partir da Teoria da Ação Comunicativa, apresentando o instrumento de tratamento mais adequado e recomendável ao litígio, transformando as relações dos envolvidos no conflito, e perpetuando uma cultura de paz, ao satisfazer as necessidades de cada um.

\section{A TEORIA DA AÇÃO COMUNICATIVA DE JÜRGEN HABERMAS}

O Poder Judiciário tem sido visualizado no centro das discussões contemporâneas, em razão da dificuldade/exaurimento da prestação de seu serviço, o que requer mudanças na estrutura física, na capacitação pessoal e, em especial, reformas políticas.

Diante disso, é alvo constante de preocupações teóricas acerca da racionalidade instrumental de aplicação do direito e da estrutura necessária para a sua realização, razão pela qual o Conselho Nacional de Justiça realiza pesquisas nas três esferas da justiça (Poder Judiciário estadual; federal; Justiça do Trabalho), no tocante ao número de processos ajuizados por ano; número de sentenças proferidas por magistrado; número de recursos em segundo grau, número de magistrados; número de servidores; verificando-se, assim, a taxa de congestionamento do Poder Judiciário brasileiro, bem como demonstrando a incapacidade da Jurisdição de monopolizar a resolução dos conflitos, apresentando-se, para tanto, formas complementares de tratamento dos conflitos, as quais conferem celeridade, informalização e pragmaticidade.

Nesse contexto, aponta-se que a crise do Judiciário perpassa por dois pontos:

1. Crise de identidade, aqui compreendida enquanto embaçamento do papel do Poder Judiciário como mediador central dos conflitos, perdendo espaço para outros centros de poder, talvez mais aptos a lidar com a complexidade dos conflitos; 
2. E crise de eficiência, vista a partir da impossibilidade de responder de modo eficiente à complexidade social e litigiosa com a qual se depara. ${ }^{3}$

Ademais, indica-se que a crise de eficiência da jurisdição decorre, também, da crise estrutural (dificuldades de infraestrutura, de pessoal, de equipamentos, de custos); crise objetiva (em decorrência da linguagem técnico-formal, utilizada nos procedimentos e ritos forenses, burocratização, morosidade e acúmulo de demandas); crise subjetiva ou tecnológica (incapacidade de lidar com as novas realidades e complexidades); e crise paradigmática (relacionada aos métodos e conteúdos utilizados pelo Direito para buscar o tratamento pacífico dos conflitos).

Dessa forma, verifica-se o distanciamento da lei da sociedade na qual se encontra inserida, a qual não corresponde com a expectativa de tratamento adequado de conflitos. Portanto, afirma-se que a perda da capacidade do Judiciário de absorver e decidir conflitos está intimamente ligada com a maior ou menor sensibilidade diante das mudanças sociais. ${ }^{4}$

Em razão do cenário descrito, o Estado deparou-se com o desafio de apresentar mecanismos que possibilitem uma convivência comunicativamente pacífica $^{5}$, motivo pelo qual se utiliza a Teoria da Ação Comunicativa de Jürgen Habermas, a qual busca uma racionalidade para responder à complexidade social. ${ }^{6}$

Para justificar a utilização da referida teoria, o próprio autor manifesta que as instituições do Estado de Direito devem garantir um exercício efetivo da autonomia política de cidadãos socialmente autônomos, possibilitando que o poder comunicativo de uma vontade formada racionalmente surja, encontrando respaldo em programas legais, circulando em toda a sociedade por meio da aplicação racional, da implementação administrativa de programas legais e desenvolvimento de sua força de integração social. ${ }^{7}$

As interações sociais são mais ou menos cooperativas e estáveis, da mesma forma mais ou menos conflituosas ou estáveis. Assim, na medida em que os atores estão exclusivamente orientados para o sucesso, ou seja, focados nas consequências do seu agir, eles buscam alcançar os objetivos de sua ação influindo externamente, seja por meio do uso de armas ou bens, ameaças ou seduções, sobre a definição da situação ou sobre as decisões ou motivos de seu adversário. Afirma-se, nessa ótica, que os sujeitos se orientam estrategicamente, a partir de como se entrosam os cálculos de ganho egocêntricos, bem como sua cooperação decorre do interesse dos participantes.

\footnotetext{
${ }^{3}$ SPENGLER, Fabiana Marion. Retalhos da Mediação. Santa Cruz do Sul: Essere nel Mondo, 2014 (recurso eletrônico acessível na página www.esserenelmondo.com).

${ }^{4}$ Idem.

${ }^{5}$ SPENGLER, Fabiana Marion. Da Jurisdição à Mediação. Por uma outra Cultura no Tratamento de Conflitos. Ijuí: editora Unijuí, 2010.

${ }^{6}$ HABERMAS, Jürgen. Agir Comunicativo e razão descentralizada. Trad. Lucia Aragão. Rio de Janeiro: Tempo Brasileiro, 2002.

${ }^{7}$ HABERMAS, Jürgen. Era das Transições. Trad. de Flávio Siebeneichler. Rio de Janeiro: Tempo Brasileiro, 2003.
} _vol.09, n. 01, Rio de Janeiro, 2016. pp. 164-180 
Por sua vez, o agir comunicativo orienta-se na harmonização interna dos planos de ação, cujas metas são perseguidas somente diante da existência de um acordo ou da negociação da situação e das consequências esperadas.

Ademais, os processos de entendimento mútuo visam um acordo que depende do assentimento racionalmente motivado ao conteúdo de uma manifestação. $\mathrm{O}$ acordo não pode ser imposto à outra parte, não pode ser extorquido ao adversário por meio de manipulações. ${ }^{8}$

A ação comunicativa pauta-se em atores capazes, por meio da linguagem, de tomarem postura diante das pretensões de validade do outro. Portanto,

Como o mundo da vida aparece desdiferenciado aos indivi囚duos, a reconstrução de uma oferta de fala leva $\mathbb{\bigotimes}_{\text {conclusa }}$ o de que as pretenso es de validade defendidas sempre estara o referenciadas aos três mundos (objetivo, social e subjetivo). Desta forma, quem oferece um ato de fala comunicativamente, ou seja, orientado $a \mathbb{X}$ cooperaça o, necessariamente fundamenta seu ato na pretensa o de que $\mathbb{\bigotimes}$ verdadeiro em relaça ${ }^{\circ}$ ao mundo objetivo, correto em relaça o o ao mundo social e veraz com relaça o o ao mundo subjetivo.?

O agir comunicativo orienta-se a partir do pano de fundo do mundo da vida, no qual o ator é as duas coisas ao mesmo tempo: ele é iniciador, pois domina as situações por meio de ações imputáveis e, ao mesmo tempo, é produto das tradições nas quais se encontra, dos grupos solidários aos quais pertence e dos processos de socialização nos quais se cria. "O mundo da vida em cada caso oferece uma provisão de obviedades culturais donde os participantes da comunicação tiram seus esforços de interpretação os modelos de exegese consentidos". ${ }^{10}$

Nesse sentido, o referido autor afirma que a expressão "agir comunicativo" traduz as interações sociais que o uso da linguagem orientado para o entendimento ultrapassa um papel coordenador da ação. "Os pressupostos idealizadores imigram, por cima de comunicação linguística, para dentro do agir orientado para o entendimento". ${ }^{11}$

Fala-se em agir comunicativo, portanto, "quando os agentes coordenam seus planos de ação mediante o entendimento mútuo linguístico, ou seja, quando eles os coordenam de tal modo que lançam mão das forças de ligação ilocucionárias próprias dos atos de fala”. ${ }^{12}$

\footnotetext{
${ }^{8}$ HABERMAS, Jürgen. Consciência Moral e Agir Comunicativo. Trad. Guido A. de Almeida. Rio de Janeiro: Tempo Brasileiro, 1989.

${ }^{9}$ RECK, Janriê Rodrigues. ASPECTOS TEOØRICO-CONSTITUTIVOS DE UMA GESTA`O PU囚BLICA COMPARTIDA:

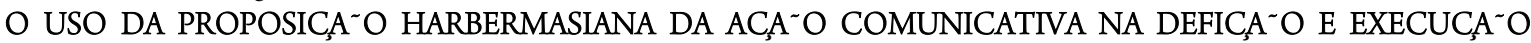
COMPARTILHADA DO INTERESSE PU『BLICO. Dissertação de Mestrado. Universidade de Santa Cruz do Sul, 2006, p. 28.

${ }^{10}$ HABERMAS, Jürgen. Op. Cit., 1989, p. 166.

${ }^{11}$ HABERMAS, Jürgen. Op. Cit., 2002, p. 72.

${ }^{12}$ HABERMAS, Jürgen. Op. Cit., 2003, p. 118.
} 
Nesse rumo, verifica-se que esses são apenas um dos componentes do mundo da vida, bem como as solidariedades dos grupos integrados por meio de valores e das competências dos indivíduos socializados, as quais servem como recursos para o agir orientado para o entendimento mútuo.

Consoante sustenta Habermas, o mundo da vida constitui

O contexto da situação da ação; ao mesmo tempo, ele fornece recursos para os processos de interpretação com os quais os participantes da comunicação procuram suprir a carência de entendimento mútuo que surgiu em cada situação de ação. Porém, se os agentes comunicativos querem executar os seus planos de ação em bom acordo, com base numa situação de ação definida em comum, eles têm que se entender acerca de algo no mundo. ${ }^{13}$

Adiciona, ainda, o referido autor que $[\ldots]$ "o mundo de vida forma um horizonte e ao mesmo tempo oferece uma quantidade de evidências culturais das quais os participantes no ato de comunicar, nos seus esforços de interpretações retiram padrões de interpretações consentidas". ${ }^{14}$

Ademais, os atos da fala não servem apenas para representação de estados e acontecimentos (mundo objetivo), mas se destinam, também, para a produção (ou renovação) de relações interpessoais, quando o falante se refere a algo do mundo social das interações legitimamente reguladas, ou, para relatar suas vivências (mundo subjetivo).

Dessa forma, os participantes da comunicação fundamentam seus esforços de entendimento mútuo em um sistema de referências formado por três mundos. Um acordo comunicativo pode se apoiar, ao mesmo tempo, em um saber proposicional compartido intersubjetivamente, em uma concordância normativa, bem como numa confiança recíproca. ${ }^{15}$

Os pressupostos de uma ação comunicativa, enquanto condições de acesso ao mundo da vida e meio de formação de consensos, podem ser resumidos diante da necessidade dos participantes terem mútua capacidade de responder por seus atos, responsabilizando-se por eles; os participantes devem estar mutuamente dispostos ao entendimento e a atuar sobre um consenso, ou seja, buscando um acordo. ${ }^{16}$

O acordo em sentido estrito somente será alcançado se os envolvidos aceitarem uma pretensão de validade pelas mesmas razões, enquanto um entendimento mútuo acontece mesmo quando um vê no outro, acima das preferências, boas razões para a intenção declarada, ou seja, razões que são boas para ele. ${ }^{17}$

Ainda, considera-se o êxito ilocucionário de um ato fala na medida em que é reconhecimento de forma intersubjetiva pela pretensão de validade levantada no meio em que se encontra. Pressupõe-se, nesse sentido, uma situação de comunicação em que os envolvidos podem assumir os papéis de falante e de ouvinte e, se necessário, de um terceiro presente, isto é, os papéis da primeira, da segunda e da terceira pessoas.

\footnotetext{
${ }^{13}$ HABERMAS, Jürgen. Op. Cit., 1989, p. 167.

${ }^{14}$ HABERMAS, Jürgen. O discurso filosófico. Rio de Janeiro: Zahar, 1990, p. 279.

${ }^{15}$ HABERMAS, Jürgen. Op. Cit., 1989.

${ }^{16}$ SPENGLER, Fabiana Marion. Op. Cit., 2010, p. 353.

${ }^{17}$ HABERMAS, Jürgen. Op. Cit., 2003.
} 
Compreende-se, assim, que "essa distribuição de papéis, prevista na lógica do sistema dos pronomes pessoais, é essencial para a racionalidade comunicativa corporificada em processos de entendimento mútuo". ${ }^{18}$

A ação comunicativa permite que a partir da força consensual dos processos linguísticos ocorra o entendimento, ou seja, a própria linguagem torna eficaz a coordenação das ações. ${ }^{19}$

Assim:

A ação comunicativa se dá a partir da prática do consenso, gerando compromissos, numa estrutura social complexa na qual a coerção, caracterizada pela possibilidade de sanção, já não serve mais como elemento condutor do agir social em relações conflituosas. Nestes termos, não obstante a importância do Direito enquanto elemento de promoção/manutenção da paz social, o consenso e a inclusão social surgem como alternativas no tratamento de controvérsias. ${ }^{20}$

Dessa forma, todo ato de fala que produz um entendimento com outra pessoa sobre algo, situa a expressão linguística em relação ao falante, ao ouvinte e ao mundo. A ação comunicativa decorre dos atos ilocucionários de fala, em que um dos aspectos é a relação interpessoal, eis que por meio dos atos de fala os participantes alcançam feitos de coordenação mediante o estabelecimento de tais relações.

A ação comunicativa opera a partir do entendimento, da coordenação da ação e da socialização, motivo pelo qual o seu estudo dá sustentabilidade ao debate contemporâneo do exaurimento da jurisdição e de meios complementares de tratamento dos conflitos, o que pode ser visualizado na proposta do professor norteamericano Frank Sander, denominada de Tribunal Múltiplas Portas, a seguir abordado.

\section{O MODELO NORTE-AMERICANO DE TRATAMENTO DE CONFLITOS: THE MULTI-DOOR COURTHOUSE SYSTEM}

Originalmente denominado de Comprehensive Justice Center ${ }^{21}$, o Multi-door Courthouse System recebeu essa denominação pela American Bar Association ${ }^{22}$ após ter sido quase que acidentalmente criado pelo professor da Universidade de Harvard, Frank Sander. O autor relata que compilou suas anotações acerca de suas reflexões com as insatisfações das Varas de Família para a resolução de disputas nesta área e, por outro lado, dos avanços verificados na arbitragem para os litígios trabalhistas, enviando-as aos seus colegas da Universidade de Harvard para comentários, porém, sem seu conhecimento, um deles encaminhou a outro colega da Universidade da Pensilvânia que, por sua vez, estava trabalhando com o Chefe da Justiça Norte-Americana, Warren Burger, os quais estavam planejando uma Conferência (1976), em homenagem ao professor Roscoe Pound (que anteriormente já havia debatido acerca da problemática da justiça), na qual buscavam debater vários assuntos

\footnotetext{
${ }^{18}$ HABERMAS, Jürgen. Verdade e Justificação. Ensaios Filosóficos. Trad. Milton Camargo Mota. São Paulo: Loyola, 2004, p. 109.

${ }^{19}$ SPENGLER, Fabiana Marion. Op. Cit., 2010.

${ }^{20}$ Idem, p. 359.

${ }^{21}$ O presente termo pode ser compreendido como "Centro Abrangente de Justiça”.

${ }^{22}$ Instituição equiparada a Ordem dos Advogados do Brasil (OAB).
} 
relacionados com a insatisfação com o sistema de administração da justiça, dentre eles a resolução de disputas, sendo Sander foi convidado para apresentar sua proposta.

Nessa oportunidade, o professor da Harvard Law School assim manifestou:

We lawyers have been far too single-minded when it comes to dispute resolution. We have tended to assume that the courts are the natural and obvious - and only - dispute resolvers. In fact there exists a rich variety of processes which may resolve conflicts far more effectively. Much as the police have been looked for to "solve" racial, school and neighborly disputes, so too have we been making greater and greater demands on the courts to resolve disputes that used to be handled by other institutions of society. Quite obviously, the courts cannot continue to respond effectively to those accelerating demands. It becomes essential therefore to examine other alternatives). ${ }^{23}$

Nesse contexto, o Multi-door Courthouse System apresenta-se como instrumento de tratamento de conflitos a fim encaminhar a demanda à abordagem mais adequada, considerando as suas peculiaridades. A recomendação de Sander consistia na criação de um sistema que oferecesse várias opções de abordagem para os conflitos trazidos pelas pessoas, ou seja, "I tried to look at each of the different processes and see whether we could work out some kind of taxonomy of which disputes ought to go where, and which doors are appropriate for which disputes". ${ }^{24}$

Ademais, consiste em:

Dar um olhar diferente para as diversas formas de tratamento do conflito, o qual poderia ser a mediação, a negociação, a arbitragem, dentre outros mecanismos. Tentou olhar para cada um dos diferentes processos e trabalhou com o tipo de taxonomia de disputas, observando quais as portas eram apropriadas para o tratamento da demanda. ${ }^{25}$

A proposta de Sander caracteriza-se por integrar, em um único local, vários modos de processamento de conflitos. Dessa forma, ao invés de apenas uma porta (processo judicial), o Tribunal Múltiplas Portas abrange um sistema mais amplo, com vários tipos de procedimentos, aos quais as partes são direcionadas de acordo com a particularidade de seu conflito. ${ }^{26}$

Como manifesta Barbosa, "a característica-chave do fórum de múltiplas portas é a sua fase inicial, no qual cada disputa é analisada de acordo com diversos critérios e encaminhada para o procedimento mais adequado. A partir daí o caso será tratado conforme o processo indicado. ${ }^{27}$

Inicialmente, realiza-se uma avaliação do conflito, por meio de pessoal especializado, identificando às

${ }^{23}$ SALES, Lilia Maia de Morais; SOUSA, Mariana Almeida de. O Sistema de Múltiplas Portas e o Judiciário Brasileiro. In: Direitos Fundamentais \& Justiça. Ano 5, n. 16. Jul./Set. 2011, p. 207

${ }^{24}$ CRESPO, Mariana Hernandez; SANDER, Frank. Evolution of the Multi- Door Courthouse. University of St. Thomas Law Journal, Saint Paul, MN, v. 5:3, p. 670, 2008. Disponível em: <http://papers.ssrn. com/sol3/papers.cfm?abstract_id=1265221>. Acesso em: 28 Mai. 2014, p. 670

${ }^{25}$ OLIVEIRA, Luthyana Demarchi de; SPENGLER, Fabiana Marion. O Fórum Múltiplas Portas como Política Pública de Acesso à Justiça e à Pacificação Social. Curitiba: Multidéia, 2013, p. 70.

26 SIFUENTES, Mônica. Tribunal multiportas. Jus Navigandi, Teresina, ano 11, n. 972, 28 fev. 2006. Disponível em: http://jus.com.br/artigos/8047/tribunal-multiportas. Acesso em: 28 Mai. 2014. s.p.

${ }^{27}$ BARBOSA, Ivan Machado. Fórum de Múltiplas Portas: uma proposta de aprimoramento processual. In: AZEVEDO, André Gomma de (Org.). Estudos em Arbitragem, Mediação e Negociação. v. 2. Brasília: Ed. Grupos de Pesquisa, 2003. Disponível em: $<$ http://vsites.unb. br/fd/gt/Volume2.pdf>. Acesso em: 23 jun. 2013. s.p. 
pessoas o método de tratamento mais adequado ao seu conflito (porta mais indicada). A importância do sistema em estudo reside em que as técnicas convivem de forma harmoniosa e articulada com o sistema de justice, recebendo o suporte e financiamento do Poder Público. ${ }^{28}$

Salienta-se a pertinência da adoção das múltiplas portas em razão de que reconhecer que partes e conflitos são melhor assistidos com métodos específicos diante das características do seu litígio. Por essa razão, afirma-se que se objetiva informar às partes acerca das alternativas disponíveis para tratamento do seu conflito, auxiliando-as na escolha do mecanismo mais apropriado para a disputa particular. ${ }^{29}$

Assim, a implementação do Múltiplas Portas é disponibilizar mecanismos para tratar os conflitos trazidos ao Poder Judiciário. Ao abordar o conflito, realiza-se uma avaliação, identificando-se as partes ou interessados para, então, apontar o instrumento mais adequado à satisfação dos interesses das pessoas envolvidas no conflito.

Ademais, destaca-se que o profissional responsável pela condução do caso pode ser um negociador, um conciliador, um mediador, um árbitro ou um juiz. O importante é identificar o método específico ao problema apresentado. $^{30}$

Na etapa seguinte, há o processo de diagnóstico do conflito, o qual pode ser dividido em duas funções principais: entrevista e aconselhamento. Na entrevista, realizam-se perguntas a fim de identificar o problema, encerrando-se a etapa com o resumo da situação e a aceitação da parte; no aconselhamento, analisam-se as soluções potenciais, com suas prováveis consequências negativas e positivas, identificando, ao final, a porta mais adequada ao tratamento do conflito.

Dessa forma, o Fórum Múltiplas Portas tem a função de receber o conflito, encaminhando-o, podendo ser visualizado como uma roda, estando localizado no seu centro a fase de entrada e a unidade de referencia; nos raios da roda, encontram-se as portas de tratamento do conflito (as opções de referência). Posteriormente à triagem e ao diagnóstico de admissão, o conflito é submetido a um dos processos de tratamento (opções), e, em não sendo bem-sucedida a primeira opção, o conflito retorna para o centro da roda, submetendo-a a nova reavaliação e após novo tratamento. ${ }^{31}$

Oliveira e Spengler referem que:

O Fórum Múltiplas Portas é um centro multifacetado cuja premissa é a aplicação do melhor mecanismo, considerando as vantagens e desvantagens do caso específico, no tratamento do conflito. Assim, em vez de apenas uma "porta" que conduz à sala de audiências, esse centro

\footnotetext{
${ }^{28}$ SALES, Lilia Maia de Morais; SOUSA, Mariana Almeida de. Op. Cit. 2011, p. 209.

${ }^{29}$ Idem, ibidem.

${ }^{30}$ NUNES, Andrine Oliveira; SALES, Lilia Maia de Moraes. A possibilidade do alcance da justiça por meio de mecanismos alternativos associados ao judiciário. 2010, CONPEDI. Disponível em: <http:// www.conpedi.org.br/manaus/arquivos/anais/florianopolis/Inte gra.pdf>. Acesso em: 23 jun. 2013. s.p.

${ }^{31}$ OLIVEIRA, Luthyana Demarchi de; SPENGLER, Fabiana Marion. Op. Cit., 2013, p. 118. 
de justiça global tem muitas portas, que podem ser a "negociação", a "conciliação", a "mediação", a "arbitragem", a "avaliação preliminar neutra", dentre outros. ${ }^{32}$

Compreende-se, portanto, que o Fórum Múltiplas Portas se caracteriza por uma mesa de entradas e um centro de diagnóstico, que a partir do relato do caso feito pelas próprias pessoas envolvidas no conflito, o profissional especializado as orienta para o meio mais adequado de tratamento.

A partir da leitura de French, verifica-se que para determinar a porta a ser indicada, devem ser observados quatro fatores:

1. A natureza da disputa;

2. O relacionamento entre as partes;

3. O valor do pedido e o valor do processo;

4. Velocidade, considerando-se a necessidade de resposta rápida e urgente intervenção. ${ }^{33}$

Dessa forma, Sander apresentou como portas de tratamento a mediação, a conciliação, a arbitragem, os processos híbridos, como a mediação e a arbitragem (med-arb ou arb-med), o mini-trial, o summary jury trial, o case evaluation, o ombudsman e a adjudicação. ${ }^{34}$

A primeira porta, denominada de mediação, consoante manifesta Spengler ${ }^{35}$, constitui-se em um processo em que o terceiro auxilia os participantes em uma situação conflitiva a tratá-la, permitindo que a solução seja aceitável para os envolvidos, bem como que satisfaça seus anseios e desejos.

Neste método, os conflitantes devem ser encorajados a ouvir e a entender os pensamentos e sentimentos uns dos outros, possibilitando que juntos alcancem uma resposta favorável a ambos. Dessa forma, a meta da mediação é responsabilizar os conflitantes pelo tratamento do litígio que os une a partir de uma ética da alteridade, encontrando, a partir do auxílio de um mediador, uma garantia de sucesso, aparando as arestas e dificuldades das partes, bem como compreendendo as emoções reprimidas e buscando um consenso que atinja o interesse das partes e a paz social. ${ }^{36}$

De fato, o principal desafio que a mediação enfrenta não é o de gerar relações calorosas e aconchegantes, sociedades isentas de litígio ou uma ordem de mundo harmoniosa. Ao invés disso, considerando-se a natureza endêmica do conflito, talvez o seu principal desafio seja encontrar mecanismo que possibilitem uma convivência comunicativamente pacífica. ${ }^{37}$

A mediação ocorre pela intervenção de um terceiro, de uma terceira pessoa que se interpõe entre os dois protagonistas de um conflito, isto é, de duas pessoas, comunidades ou povos que se confrontam e estão um contra o outro. Assim, a mediação busca passar os dois protagonistas da adversidade à conversação, levando-os a virar-se

\footnotetext{
32 Idem, p. 113.

${ }^{33}$ FRENCH, Robert. Perspectives on Court Annexed Alternative Dispute Resolution. Law Council of Australia — Multi-Door Symposium. 2009. Disponível em: http://www.hcourt.gov.au/assets/publications/speeches/currentjustices/frenchcj/frenchcj27july09.pdf. Acesso em: 28 Mai. 2014, p. 03.

${ }^{34}$ OLIVEIRA, Luthyana Demarchi de; SPENGLER, Fabiana Marion. Op. Cit., 2013, p. 113.

${ }^{35}$ SPENGLER, Fabiana Marion. Op. Cit., 2010.

${ }^{36}$ SPENGLER, Fabiana Marion. Fundamentos Políticos da Mediação Comunitária. Ijuí: editora Unijuí, 2012.

${ }^{37}$ Idem, p. 94.
} 
um para o outro para se falarem, compreenderem e, se possível, construir juntos um compromisso que abra caminho à reconciliação. ${ }^{38}$

O terceiro mediador trabalha para criar um espaço intermediário que possibilita que os envolvidos no conflito possam descansar dele e recriar as suas relações fundamentadas na paz. "A mediação quer, assim, criar na sociedade um lugar onde os adversários possam aprender ou reaprender a comunicar, a fim de chegarem a um pacto que lhes permita viver juntos, se não numa paz verdadeira, pelo menos numa coexistência pacífica". ${ }^{39}$

Escolher a mediação é, para cada um dos dois adversários, compreender que o desenvolvimento da sua hostilidade só lhes pode ser prejudicial e que têm todo o interesse em tentar encontrar, por meio de um acordo amigável, uma saída positiva para o conflito que os opõe. [...] A maior parte das vezes, as decisões da justiça cortam o nó de um conflito, designando um ganhador e outro perdedor - um ganha o seu processo o outro perde-o - e as duas partes saem do tribunal mais adversárias do que nunca. A mediação não se preocupa tanto em julgar um facto passado - que é o que faz a instituição judicial - como em apoiar-se nele para o ultrapassar e permitir que os adversários de ontem inventem um futuro liberto do peso de seu passado. ${ }^{40}$

O mediador não tem por função pronunciar um veredicto, nem enunciar uma condenação, bem como qualquer poder de coação que permita impor uma solução aos protagonistas de um conflito. Ainda, consoante reflete o autor, o mediador não é aquele que toma partido por nenhum dos dois conflitantes, mas aquele que toma partido por ambos. "Neste sentido, o mediador não é neutro, ele é equitativo: esforça-se por dar a cada um o que lhe é devido." ${ }^{\text {11 }}$

A intervenção de um terceiro (magistrado, por exemplo) na resolução do conflito poderá, de maneira geral, oferecer maiores chances de sucesso? Nesse caso, que características essa terceira parte, incluindo seu relacionamento com os conflitantes, determina a aceitabilidade de sua intervenção? Que características desse terceiro ajudam a resolver conflitos e quais são as que promovem impasse e um litígio interminável? Se abordados por um igual, que pertence à mesma comunidade e possui valores, hábitos e crenças comuns aos conflitantes, os conflitos podem ser tratados de maneira mais adequada? Entre iguais, a chance de autonomização e responsabilização pelo tratamento de litígios são reais? (SPENGLER, 2012, p. 199-200)

O mediador tem um poder limitado ou um poder não autoritário de decisão, ou seja, não pode unilateralmente determinar ou forçar as partes a resolver as suas diferenças, provocando a decisão. Estas características são as que distinguem o papel do mediador do juiz ou do árbitro, pois os dois últimos detêm o poder de tomada de decisão para as partes, fundamentados por contratos, normas e leis. Para Moore ${ }^{42}$, enquanto o juiz examina o passado e avalia acordos pactuados entre as partes ou violações de um para o outro.

The mediator, on the other hand, works to reconcile the competing interests of the two parties. The mediator's tasks are to assist the parties in examining their interests and needs, to

\footnotetext{
${ }^{38}$ MULLER, Jean - Marie. Não-violência na educação. Tradução de Tônia Van Acker. São Paulo: Palas Athenas, 2006.

${ }^{39}$ Idem, p. 170.

${ }^{40}$ Idem, p. 171.

${ }^{41}$ Idem, p. 172.

${ }^{42}$ MOORE, Christopher W. The Mediation Process. Practical Strategies for Resolving Conflict. San Francisco: Jossey-Bass, 2003. vol.09, nº. 01, Rio de Janeiro, 2016.pp. 164-180 
help them negotiate an exchange of promises, and to redefine their relationship in a way that will be mutually satisfactory and will meet their standards of fairness. ${ }^{43}$

A segunda porta, chamada de conciliação, é entendida como a atividade desenvolvida para incentivar, facilitar e auxiliar as partes à autocomposição, porém adotam metodologia que permite a apresentação de proposição por parte do conciliador. Nesse rumo, "tem como método a participação mais efetiva desse terceiro na proposta de solução, tendo por escopo a só solução do conflito que lhe é concretamente apresentado nas petições das partes”. ${ }^{44}$

A conciliação oportuniza às partes um debate e posterior exploração das possibilidades de resolução aceitáveis a todos. Por essa razão, bem como pela tradição história diante dos demais métodos, este procedimento tende a ser o mais utilizado pelo Fórum de Múltiplas Portas.

Apontam-se como vantagens a pacificação social, pois diverso do que se verifica na sentença judicial, "o acordo da conciliação não é imposto autoritariamente e logra ventilar emoções das partes para acalmá-las, podendo atingir a lide sociológica, em geral mais ampla do que aquela que emergiu "como simples ponta do iceberg" ${ }^{45}$

Adiciona-se à função de pacificação social, a racionalização da aplicação da Justiça com a consequente redução do congestionamento dos juízos, educação da população na negociação de suas próprias disputas, aumento da legitimidade do Poder Judiciário e intensificação da participação democrática popular nos casos em que o conciliador é escolhido entre a comunidade. ${ }^{46}$

A seu turno, a terceira porta, arbitragem, consiste na escolha pelas partes de um terceiro, denominado de árbitro, independente e imparcial, o qual é responsável por proferir a decisão equivalente à sentença judicial. ${ }^{47}$ Assim, conceitua-se arbitragem como o meio pelo qual o Estado, ao invés de interferir diretamente nos conflitos de interesses, impondo a sua decisão, permite que uma terceira pessoa o faça, a partir de um procedimento e da observação de regras mínimas, mediante uma decisão com autoridade idêntica à de uma sentença judicial. Dessa forma, as partes, ao optarem pela arbitragem, afastam a jurisdição estatal, e substituem por outra estratégia de tratamento de conflitos, reconhecida e regulada pelo Estado, permitindo a execução das decisões proferidas, bem como sejam anuladas aquelas que não tenham observado um mínimo de regras exigidas pelo legislador. ${ }^{48} \mathrm{O}$ terceiro, denominado de árbitro, tem total confiança das partes, recebendo destas autoridades suficientes para impor uma solução satisfatória.

Indicam-se as seguintes características para a arbitragem:

\footnotetext{
${ }^{43}$ Idem, p. 18.

${ }^{44}$ CALMON, Petrônio. Fundamentos da Mediação e da Conciliação. Rio de Janeiro: Forense, 2008, p. 144.

${ }^{45}$ BARBOSA, Ivan Machado. Op. Cit., 2008, s.p.

${ }^{46}$ Idem, ibidem

${ }^{47}$ OLIVEIRA, Luthyana Demarchi de; SPENGLER, Fabiana Marion. Op. Cit., 2013, p. 96.

${ }^{48}$ MORAIS, José Luis Bolzan de; SPENGLER, Fabiana Marion. Mediação e Arbitragem: alternativas à jurisdição. 3. ed. Porto Alegre: Livraria do Advogado, 2012.
} 
1. Ampla liberdade de contratação - as partes definem o objeto de litígio e podem escolher até mesmo as regras de direito substantivo e adjetivo aplicável a ele;

2. Pode ser usada em qualquer controvérsia que envolva direito patrimonial disponível - tendo as partes capacidade civil, as partes podem escolher livremente os árbitros a quem confiem para que deem tratamento ao litígio;

3. Permite ao árbitro disciplinar o procedimento caso não haja convenção das partes neste sentido permite uma maior celeridade no tratamento dos conflitos, bem como a exigência do sigilo do procedimento arbitral;

4. Transforma a sentença arbitral em título executivo judicial - o que a torna eficaz como sentença declaratória ou constitutiva.

Nesse sentido, consoante manifestam Goldberg, Sander, Rogers e Cole ${ }^{49}$, a arbitragem apresenta as seguintes vantagens:

1. Terceiro/árbitro com conhecimento especializado;

2. Reconhecimento/legitimidade da decisão;

3. Privacidade do procedimento;

4. Informalidade do procedimento;

5. Baixo custo; e

6. Rapidez.

Por sua vez, a avaliação preliminar neutra (Early Neutral Evaluation), quarta porta aqui apresentada, caracteriza-se por fornecer às partes um parecer fundamentado por um advogado, juiz ou promotor de justiça. Trata-se, portanto, de uma avaliação prévia mediante uma opinião fundamentada de forma oral..$^{50}$ Assim,

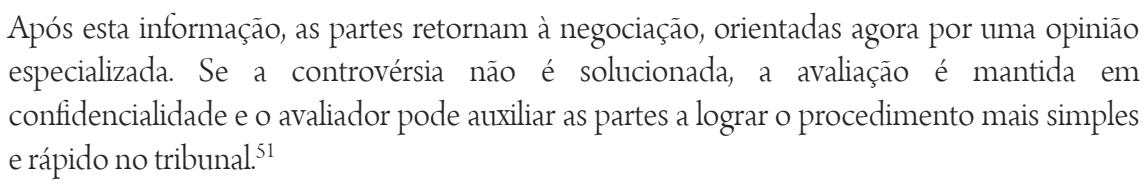

O Summary Jury Trial configura-se em um procedimento sumário diante de um Júri, para verificação da tese e da reação dos jurados, os quais, geralmente, não possuem conhecimento do seu papel consultivo. Assim, "o procedimento é sumário e conta com um resumo das teses e provas, sendo o júri chamado para emitir um parecer opinativo. Normalmente, é um mecanismo utilizado para casos complexos que demandem tempo e alto custo".52

Há, ainda, o Mini-Trial, o qual consiste em apresentações sumários realizadas pelos advogados de cada parte a um painel composto por um conselheiro neutro e executivos, buscando negociar a resolução da disputa. Se

${ }^{49}$ GOLDBERG, Stephen B.; Frank E. A. Sander; ROGERS, Nancy H.; COLE, Sarah Rudolph. Dispute Resolution. Negotiation, Mediation, and other Processes. 5. ed. New York: Aspen Publishers, 2007.

${ }^{50}$ OLIVEIRA, Luthyana Demarchi de; SPENGLER, Fabiana Marion. Op. Cit., 2013.

${ }^{51}$ BARBOSA, Ivan Machado. Op. Cit., 2008, s.p.

${ }^{52}$ OLIVEIRA, Luthyana Demarchi de; SPENGLER, Fabiana Marion. Op. Cit., 2013, p. 103. 
forem incapazes de fazê-lo, podem solicitar um conselheiro neutro para dar uma previsão de resultado possível do litígio.

A Court-annexed arbitration utiliza arbitragem anexa ao juízo tradicional, ou seja, as partes são incentivadas e encorajadas a participar da arbitragem como mecanismo de tratamento do conflito.

No Med-Arb, e Arb-Med, as partes anuem em realizar a mediação ou a arbitragem e, inexitosa, passa-se ao outro procedimento. Tratam-se de procedimentos privados e espontâneos, os quais podem ser realizados sob orientação coordenada.

Destaca-se que no processo med-arb, a função neutra se dá primeiro como mediador. Se falhar a mediação, a mesma pessoa neutral servirá como árbitro, porém, neste caso, emitindo decisão. Por sua vez, na arbmed, ocorre o contrário. Isto é, realiza-se o procedimento de arbitragem, alcançando-se a sentença, sem anunciá-la às partes, iniciando-se, antes, os procedimentos de mediação. ${ }^{53}$

A porta denominada de Ombudsman (Ouvidor) caracteriza-se por ser uma pessoa nomeada por uma instituição para tutelar seus direitos contra a falta, disfunção, abusos ou retardos desta mesma instituição. Destacase que ela não possui o poder de impor uma decisão, nem de anular, revogar, modificar os atos da instituição, porém atua formulando observações e recomendações, buscando a satisfação das reclamações dos interessados. ${ }^{54}$

Estudos mais recentes apontam duas inovações no sistema múltiplas portas, salientando-se que o fórum não se limita a um número determinado de portas, podendo novas surgir diante da evolução dos conflitos e da própria sociedade.

Nessa ótica, aponta-se a porta denominada de Collaborative Law (Direito Colaborador), cuja aplicabilidade se dá no Direito de Família, quando o casal, durante o processo de divórcio, concorda em realizar um acordo sem recorrer ao Poder Judiciário. A diferença dessa porta das demais negociações com advogados, por exemplo, reside no fato de que, inicialmente, as partes (casal) assinem um acordo de participação. Após, devem trocar informações financeiras completas, de forma que cada parte possa ter total acesso às informações e, portanto, tomar decisões sem alcançar um litígio judicial.

Outra nova porta, chamada de Parenting Coordination (Coordenação Familiar), é um mecanismo utilizado em conflitos na guarda de filhos diante de pais divorciados. Dessa forma, o método busca auxiliar os pais no cumprimento da decisão judicial, bem como educar os pais na observação do impacto do conflito no seu filho. ${ }^{55}$

A porta mais tradicional, adjudicação, configura-se no litígio da parte que procura o Poder Judiciário, propondo a ação judicial, o qual é decidido pelo terceiro, aqui denominado de juiz, cuja decisão possui efeito

\footnotetext{
${ }^{53}$ Idem, p. 102-106.

${ }^{54}$ CALMON, Petrônio. Op. Cit., 2008, p. 108.

${ }^{55}$ SALES, Lilia Maia de Morais; SOUSA, Mariana Almeida de. Op. Cit. 201 1, p. 214.
} 
coercitivo, e atinge a todos os fatos do processo. Conforme manifestam Moraes e Spengler ${ }^{56}$, o caráter contencioso caracteriza o modelo da porta em estudo. Ademais, "[...] tratar o conflito judicialmente é atribuir ao magistrado o poder de dizer quem ganha e quem perde no litígio". 57

Destaca-se que justamente em razão da crítica existente com a porta da jurisdição tradicional que novos métodos surgiram, com o escopo de atender as especificidades de cada conflito. No entanto, não se está aqui excluindo da apreciação do Poder Judiciário toda e qualquer questão, apenas se objetiva adequar o tratamento ao tipo de conflito, razão pela qual Lagos, na Nigéria, enfrentou diversas dificuldades e encontrou no sistema das Múltiplas Portas alternativas aos obstáculos do seu sistema de justiça, o que será abordado no tópico seguinte.

Assim, conhecido como "Palácio de Justiça Múltiplas Portas" ou "Fórum Múltiplas Portas", os tribunais foram estabelecidos, de forma experimental e inicial, em Tulsa, Okalahoma, Houston, Texas, e no Tribunal Superior do Distrito de Columbia. Outros projetos piloto foram iniciados em Nova Jersey e Cambridge.

The programs were designed to function as an integral part of the administration of the courts and to divert cases to the most appropriate 'door' using screening criteria suggested by Sander and further developed in each project. Unlike individual court-annexed dispute resolution programs, the multi-door model provides a coordinated approach to dispute resolution with intake and referral operating under one centralized program, rather than independently. Flexibility, which enables each system to adapt the multi-door concept, has been a hallmark of these programs. ${ }^{58}$

A partir dessas experiências, a ideia espalhou-se para outros Tribunais no mundo todo.

\section{CONSIDERAÇÕES FINAIS}

A sociedade é movida por conflitos, os quais decorrem de fatores tecnológicos, políticos, econômicos e sociais, nascendo de uma disputa de ideias, valores ou interesses. Ao mesmo tempo em que pode produzir a evolução do ser humano, quando não administrado, ou pela má compreensão dos limites, instrumentos de tratamento de conflitos devem ser utilizados a fim de possibilitar que deste encontro de ideias, valores e interesses possa transformar as estruturas sensíveis às dinâmicas das relações humanas.

No conflito institucionalizado, cabe ao Estado, por meio do Poder Judiciário, decidi-lo, seja por meio de uma sentença, prolatada por um magistrado, ou, como é o caso do presente trabalho, de meios complementares que atendam às especificidades do litígio apresentado.

Nessa ótica, inseriu-se a Teoria da Ação Comunicativa a partir da ideia de que a interação do homem com o seu mundo decorre das pessoas que se manifestam na sua vida, pois o sujeito é observador e participante das interações sociais. Ainda, argumenta-se que as ações comunicativas formam uma rede que sustenta o mundo da vida e constitui o meio pela qual se reproduzem as formas concretas de vida.

\footnotetext{
${ }^{56}$ MORAIS, José Luis Bolzan de; SPENGLER, Fabiana Marion. Op. Cit, 2012.

${ }^{57}$ OLIVEIRA, Luthyana Demarchi de; SPENGLER, Fabiana Marion. Op. Cit., 2013, p. 109.

${ }^{58}$ FRENCH, Robert. Op. Cit., 2009, p. 05-06.
} 
Assim, o surgimento do Tribunal Múltiplas Portas nos Estados Unidos decorre da busca por alternativas à incerteza do direito; à lentidão/morosidade do processo; e aos altos custos. Dessa forma, afirma-se que o Fórum Múltiplas Portas se constitui em uma política pública de tratamento de conflito, constituindo-se como um centro de resolução de conflitos que oferece um conjunto de serviços, um sistema de justiça mais eficaz em lidar com o conjunto completo de disputas que surgem diante dos Tribunais.

Nessa ótica, vislumbra-se o papel emancipador possibilitado pela Teoria da Ação Comunicativa, fundamentado na satisfação das expectativas humanas essenciais, apresentando medidas terapêuticas para discutir os conflitos e encontrar respostas satisfatórias aos envolvidos, por meio de um entendimento mútuo.

Sustenta-se, assim, que pela Teoria da Ação Comunicativa, a qual instrumentaliza a ética do discurso, as pessoas são capazes de se comunicar entre si e alcançar o bem comum, um entendimento consensuado.

\title{
CONTRIBUTIONS OF THE THEORY OF COMMUNICATIVE ACTION OF JÜRGEN HABERMAS IN ADDITIONAL RESOURCES OF TREATMENT OF CONFLICTS: THE STUDY OF MULTIDOORCOURTHOUSE SYSTEM
}

\begin{abstract}
This article analyses the Communicative Action Theory contribution to the complimentary methods of conflict treatment through the study of the Multidoor Courthouse System. In order to perform this study, it is adopted the hypothetical-deductive method of approach, and the monographic method of procedure. Thus, it is related the Jürgen Habermas' theory as a way to empower and emancipate the parties of a conflict, making possible to accomplish the Multidoor Courthouse System objective, which is to present the most appropriate treatment to the conflict.
\end{abstract}

Keywords: Communicative Action; Conflict Treatment; Multidoor Courthouse System.

\section{REFERENCIAS}

BARBOSA, Ivan Machado. Fórum de Múltiplas Portas: uma proposta de aprimoramento processual. In: AZEVEDO, André Gomma de (Org.). Estudos em Arbitragem, Mediação e Negociação. v. 2. Brasília: Ed. Grupos de Pesquisa, 2003. Disponível em: <http://vsites.unb. br/fd/gt/Volume2.pdf $>$. Acesso em: 23 jun. 2013.

CALMON, Petrônio. Fundamentos da Mediação e da Conciliação. Rio de Janeiro: Forense, 2008, p. 144.

CRESPO, Mariana Hernandez; SANDER, Frank. Evolution of the Multi- Door Courthouse. University of St. Thomas Law Journal, Saint Paul, MN, v. 5:3, p. 670, 2008. Disponível em: <http://papers.ssrn. com/ sol3/papers.cfm?abstract_id=1265221>. Acesso em: 28 Mai. 2014. 
FRENCH, Robert. Perspectives on Court Annexed Alternative Dispute Resolution. Law Council of Australia Multi-Door Symposium. 2009. Disponível em: http://www.hcourt.gov.au/assets/publications/speeches/current-justices/frenchcj/frenchcj27july09.pdf. Acesso em: 28 Mai. 2014.

GABBAY, Daniela Monteiro. Mediação \& Judiciário no Brasil e nos EUA. Brasília: Gazeta Jurídica, 2013.

GOLDBERG, Stephen B.; Frank E. A. Sander; ROGERS, Nancy H.; COLE, Sarah Rudolph. Dispute Resolution. Negotiation, Mediation, and other Processes. 5. ed. New York: Aspen Publishers, 2007.

HABERMAS, Jürgen. Consciência Moral e Agir Comunicativo. Trad. Guido A. de Almeida. Rio de Janeiro: Tempo Brasileiro, 1989.

Agir Comunicativo e razão descentralizada. Trad. Lucia Aragão. Rio de Janeiro: Tempo Brasileiro, 2002.

Era das Transições. Trad. de Flávio Siebeneichler. Rio de Janeiro: Tempo Brasileiro, 2003.

Verdade e Justificação. Ensaios Filosóficos. Trad. Milton Camargo Mota. São Paulo: Loyola, 2004.

O discurso filosófico. Rio de Janeiro: Zahar, 1990.

MOORE, Christopher W. The Mediation Process. Practical Strategies for Resolving Conflict. San Francisco: Jossey-Bass, 2003.

MORAIS, José Luis Bolzan de; SPENGLER, Fabiana Marion. Mediação e Arbitragem: alternativas à jurisdição. 3. ed. Porto Alegre: Livraria do Advogado, 2012.

MULLER, Jean-Marie. Não-violência na educação. Tradução de Tônia Van Acker. São Paulo: Palas Athenas, 2006.

NUNES, Andrine Oliveira; SALES, Lilia Maia de Moraes. A possibilidade do alcance da justiça por meio de mecanismos alternativos associados ao judiciário. 2010, CONPEDI. Disponível em: <http:// www.conpedi.org.br/manaus/arquivos/anais/florianopolis/Inte gra.pdf>. Acesso em: 23 jun. 2013.

OLIVEIRA, Luthyana Demarchi de; SPENGLER, Fabiana Marion. O Fórum Múltiplas Portas como Política Pública de Acesso à Justiça e à Pacificação Social. Curitiba: Multidéia, 2013.

RECK, Janriê Rodrigues. Aspectos teoØrico-constitutivos de uma gesta o pu囚blica compartida: o uso da proposiça o harbermasiana da aça o comunicativa na defiçã o e execuça o compartilhada do interesse pu囚blico. Dissertação de Mestrado. Universidade de Santa Cruz do Sul, 2006.

SALES, Lilia Maia de Morais; SOUSA, Mariana Almeida de. O Sistema de Múltiplas Portas e o Judiciário Brasileiro. In: Direitos Fundamentais \& Justiça. Ano 5, n. 16. Jul./Set. 2011.

SIFUENTES, Mônica. Tribunal multiportas. Jus Navigandi, Teresina, ano 11, n. 972, 28 fev. 2006. Disponível em: http://jus.com.br/artigos/8047/tribunal-multiportas. Acesso em: 28 Mai. 2014.

SPENGLER, Fabiana Marion. Da Jurisdição à Mediação. Por uma outra Cultura no Tratamento de Conflitos. Ijuí: editora Unijuí, 2010.

Fundamentos Políticos da Mediação Comunitária. Ijuí: editora Unijuí, 2012.

Retalhos da Mediação. Santa Cruz do Sul: Essere nel Mondo, 2014 (acessível em www.esserenelmondo.com). 
Trabalho enviado em 18 de agosto de 2015. Aceito em 12 de outubro de 2015. 